\title{
Multicenter phase II study on cisplatin, pemetrexed, and bevacizumab followed by maintenance with pemetrexed and bevacizumab for patients with advanced or recurrent nonsquamous non-small cell lung cancer: MAP study
}

Yasuhiro Tsutani ${ }^{1}$ D, Y Yoshihiro Miyata' ${ }^{1}$, Takeshi Masuda², Kazunori Fujitaka², Mihoko Doi ${ }^{3}$, Yoshikazu Awaya ${ }^{4}$, Shoichi Kuyama ${ }^{5}$, Soichi Kitaguchi ${ }^{6}$, Kazuhiro Ueda ${ }^{7}$, Noboru Hattori ${ }^{2}$ and Morihito Okada ${ }^{1 *}$

\begin{abstract}
Background: We evaluated the safety and efficacy of induction chemotherapy with bevacizumab followed by maintenance chemotherapy with bevacizumab for advanced non-small cell lung cancer (NSCLC) in this multicenter phase II study.

Methods: Chemotherapy-naïve patient with stage IIIB-IV or recurrent nonsquamous NSCLC were eligible. We planned approximately four cycles of induction cisplatin $\left(75 \mathrm{mg} / \mathrm{m}^{2}\right)$, pemetrexed $\left(500 \mathrm{mg} / \mathrm{m}^{2}\right)$, and bevacizumab $(15 \mathrm{mg} / \mathrm{kg})$ followed by maintenance with pemetrexed $\left(500 \mathrm{mg} / \mathrm{m}^{2}\right)$ and bevacizumab $(15 \mathrm{mg} / \mathrm{kg})$ until disease progression. Progression-free survival (PFS) was the primary endpoint.
\end{abstract}

Results: Forty patients received a median of four induction chemotherapy cycles. Of them, 35 (87.5\%) patients received a median of nine maintenance chemotherapy cycles. The objective response was $70.6 \%$, and the disease control rate was $97.1 \%$. The median PFS was 10.8 (95\% Cl, 9.0-12.6), and overall survival was 48.0 (95\% Cl, 32.9-63.1) months. Median PFS of 23 patients with epidermal growth factor receptor (EGFR) mutations and of 16 patients without EGFR mutations were $12.9(95 \% \mathrm{Cl}, 9.4-16.3)$ and $7.9(95 \% \mathrm{Cl}, 1.1-14.7)$ months, respectively. Toxicities graded $\geq 3$ included neutropenia (15\%), anemia (15\%), hypertension (7.5\%), anorexia (7.5\%), fatigue (7.5\%), thromboembolic events (5\%), jaw osteonecrosis (5\%), nausea (2.5\%), oral mucositis $(2.5 \%)$, tumor pain (2.5\%), hyponatremia (2.5\%), and gastrointestinal perforation (2.5\%). Treatment-related deaths were not found.

Conclusions: In patients with advanced or recurrent nonsquamous NSCLC, induction chemotherapy with cisplatin, pemetrexed, and bevacizumab followed by maintenance chemotherapy with pemetrexed and bevacizumab is safe and effective regardless of their EGFR mutation status.

Trial registration: UMIN Clinical Trial Registry: UMIN000005569. Registered date: May 8, 2011.

\footnotetext{
* Correspondence: morihito@hiroshima-u.ac.jp

${ }^{1}$ Department of Surgical Oncology, Research Institute for Radiation Biology

and Medicine, Hiroshima University, 1-2-3 Kasumi, Minami-ku, Hiroshima

734-8551, Japan

Full list of author information is available at the end of the article
}

(c) The Author(s). 2018 Open Access This article is distributed under the terms of the Creative Commons Attribution 4.0 International License (http://creativecommons.org/licenses/by/4.0/), which permits unrestricted use, distribution, and reproduction in any medium, provided you give appropriate credit to the original author(s) and the source, provide a link to the Creative Commons license, and indicate if changes were made. The Creative Commons Public Domain Dedication waiver (http://creativecommons.org/publicdomain/zero/1.0/) applies to the data made available in this article, unless otherwise stated. 


\section{Background}

Vascular endothelial growth factor (VEGF) is a strong stimulator of endothelial cell proliferation. It is required for maintaining tumor vasculature in various tumor types $[1,2]$. Bevacizumab is a recombinant humanized monoclonal antibody, and it inhibits binding of VEGF to its receptor [2]. Combination therapies of bevacizumab and platinum-based doublet chemotherapy followed by bevacizumab maintenance as a first-line treatment are more superior than platinum-based doublet chemotherapy with respect to the overall survival (OS) and progression-free survival (PFS) in patients with advanced nonsquamous non-small cell lung cancer (NSCLC) in randomized controlled trials, such as the Eastern Cooperative Oncology Group (ECOG) E4599 and AVAiL $[3,4]$. A phase III trial that compared front-line cisplatin and gemcitabine with cisplatin and pemetrexed demonstrated a treatment-by-histology interaction, showing an improvement in OS with cisplatin and pemetrexed in patients with nonsquamous NSCLC [5]. Thereafter, in a large, randomized, phase III study, it was revealed that maintenance chemotherapy with pemetrexed was effective and was well-tolerated in patients with advanced nonsquamous NSCLC in whom the cancer did not show progression after induction chemotherapy with pemetrexed and cisplatin [6]. We hypothesized that induction therapy with cisplatin, pemetrexed, and bevacizumab followed by pemetrexed and bevacizumab maintenance would result in better survival in patients with advanced nonsquamous NSCLC. At the time of trial design in 2010, results of the AVAPERL [the randomized phase III study comparing the efficacy of maintenance therapy with bevacizumab $(7.5 \mathrm{mg} / \mathrm{kg})$ with that of maintenance therapy with bevacizumab $(7.5 \mathrm{mg} / \mathrm{kg})$ plus pemetrexed $\left(500 \mathrm{mg} / \mathrm{m}^{2}\right)$ after induction therapy with cisplatin (75 $\left.\mathrm{mg} / \mathrm{m}^{2}\right)$, pemetrexed $\left(500 \mathrm{mg} / \mathrm{m}^{2}\right)$, and bevacizumab $(7.5 \mathrm{mg} / \mathrm{kg})$ ] had not been reported [7].

In the present phase II trial, we aimed to evaluate the safety and efficacy of induction therapy with cisplatin $\left(75 \mathrm{mg} / \mathrm{m}^{2}\right)$, pemetrexed $\left(500 \mathrm{mg} / \mathrm{m}^{2}\right)$, and bevacizumab $(15 \mathrm{mg} / \mathrm{kg})$ followed by maintenance therapy with pemetrexed $\left(500 \mathrm{mg} / \mathrm{m}^{2}\right)$ and bevacizumab $(15 \mathrm{mg} / \mathrm{kg})$ in patients with advanced or recurrent nonsquamous NSCLC.

\section{Methods}

\section{Eligibility criteria}

Patients were required to have nonsquamous NSCLC and have not received any prior systemic chemotherapy, except preoperative/postoperative adjuvant chemotherapy or EGFR-tyrosine kinase inhibitor (TKI), with stage IIIB, stage IV, or recurrence disease after surgery; have measurable lesion that met the Response Evaluation Criteria in Solid Tumors (RECIST) version 1.1 [8]; be aged from 20 to 74 years; ECOG performance status of 0 or 1 ; and have adequate organ function within 1 week before study entry. The laboratory value requirements were as follows: hemoglobin level $\geq 9 \mathrm{~g} / \mathrm{dl}$, absolute neutrophil count $\geq 1500 / \mathrm{mm}^{3}$, platelet count $\geq 100,000 / \mathrm{mm}^{3}$, serum bilirubin levels $\leq 1.5 \mathrm{mg} / \mathrm{dl}$, serum aspartate aminotransferase and alanine aminotransferase levels < $100 \mathrm{IU} / \mathrm{l}$, and serum creatinine levels $\leq 1.5 \mathrm{mg} / \mathrm{dl}$; have an estimated life expectancy of at least 90 days; and have signed the document of informed consent.

Patients were not eligible if they had metastases of the central nervous system or prior therapies for brain metastasis; had received radiotherapy for lung lesions; had a history of cardiac effusion that required treatment; had another active malignancy; had a history of hemoptysis or hemosputum; had a complication related to a bleeding episode, such as bleeding diathesis, an evidence of major thoracic blood vessel involvement, an evidence of cavity formation in the lung lesion, or an evidence of thrombosis; needed an anti-thrombosis drug during the study or were administered an anti-thrombosis drug within 10 days before enrollment; had a history of brain vascular disease with symptom, gastrointestinal perforation, diverticulitis, or fistula, symptomatic heart failure, unstable angina or arrhythmia that required treatment, cardiac infarction within 1 year before enrollment, any evidence of interstitial lung disease, superior vena cava syndrome, a cord compression, a serious non-healing wound or unhealed bone fracture, an uncontrollable ulcer, uncontrollable hypertension, or a serious concomitant active infection that needed antibiotics; had known sensitivity to any component of platinum or monoclonal antibody drugs; or pregnancy or lactation.

The current study (UMIN000005569) was planned on the basis of the Declaration of Helsinki and Good Clinical Practice guidelines and was approved by the institutional review boards of all participating hospitals. Signed informed consent forms were obtained from the patients.

\section{Treatment and evaluation}

Prior to the administration of pemetrexed, all patients received folic acid and vitamin B12 supplementation and standard premedication with dexamethasone $[2,9,10]$. Patients received induction chemotherapy on day 1 of each 21-daycycle comprising cisplatin $\left(75 \mathrm{mg} / \mathrm{m}^{2}\right)$, pemetrexed $\left(500 \mathrm{mg} / \mathrm{m}^{2}\right)$, and bevacizumab $(15 \mathrm{mg} / \mathrm{kg})$. Induction chemotherapy was repeated every 3 weeks for a maximum of four cycles. After completion of at least three cycles of induction chemotherapy, patients underwent maintenance chemotherapy on day 1 of the 21-day cycle comprising pemetrexed $\left(500 \mathrm{mg} / \mathrm{m}^{2}\right)$ and bevacizumab $(15 \mathrm{mg} / \mathrm{kg})$. Every 3 weeks, maintenance chemotherapy was repeated until disease progression or intolerance. 
Using the National Cancer Institute Common Toxicity Criteria version 4.0, patients were evaluated every 21 days to assess toxicity. Tumor response was assessed using computed tomography; it was performed every 6 weeks for 24 weeks and every 6 weeks thereafter until disease progression. The original RECIST criteria (version 1.1) were used to assess the response [8]. Central review of radiologic assessment was not performed.

\section{Statistical methods}

PFS, defined as the time from enrollment to disease progression (as assessed by the investigator) or to death, was the primary endpoint of the study. OS, objective response rate, and toxicity were the secondary endpoints. A median PFS of at least 7 months compared with the historic rate of 4.8 months [5] would be considered as a favorable outcome. We estimated that 35 patients were needed to achieve an $80 \%$ power with a one-sided 0.1 level test in this single-stage, single-arm trial. An intent-to-treat approach was followed for analyzing all data. KaplanMeier method was used to calculate survival distributions. All statistical analyses were performed using the Statistical Package for the Social Sciences software (version 24.0; IBM, Armonk, NY, USA). A $p$ value of $<0.05$ was considered to be significant.

Table 1 Patients' characteristics

\begin{tabular}{lll}
\hline & & $n=40$ \\
\hline Age (range) & Male & $64.5(34-73)$ \\
& Female & $23(57.5 \%)$ \\
Performance status & 0 & $17(42.5 \%)$ \\
& 1 & $34(85.0 \%)$ \\
Smoking history & Yes & $6(15.0 \%)$ \\
Histology & Adenocarcinoma & $23(57.5 \%)$ \\
& Pleomorphic carcinoma & $38(95.0 \%)$ \\
Stage & Non-small cell lung cancer & $1(2.5 \%)$ \\
& IIIB & $1(2.5 \%)$ \\
& IV & $30(75.0 \%)$ \\
EGFR mutation & Postoperative recurrence & $9(22.5 \%)$ \\
& Positive & $23(57.5 \%)$ \\
& Negative & $16(40.0 \%)$ \\
Previous adjuvant & Unknown & $1(2.5 \%)$ \\
Chemotherapy & Yes & $6(15.0 \%)$ \\
therapy & & $8(20.0 \%)$ \\
\hline EGFR epidermal growth factor receptor, TKI tyrosine kinase inhibitor
\end{tabular}

EGFR epidermal growth factor receptor, TKI tyrosine kinase inhibitor
Table 2 Chemotherapy administration and objective response

\begin{tabular}{lll}
\hline Induction therapy $(n=40)$ & Median cycle (range) & $\begin{array}{l}4 \\
(1-4)\end{array}$ \\
Maintenance therapy $(n=35)$ & Median cycle (range) & 9 \\
& & $(1-54)$ \\
Response $(n=34)$ & CR & $0(0 \%)$ \\
& PR & $24(70.6 \%)$ \\
& SD & $9(26.5 \%)$ \\
& PD & $1(2.9 \%)$ \\
\hline
\end{tabular}

\section{Results}

\section{Patients' characteristics}

We enrolled 40 eligible patients [median age, 64.5 years; $57.5 \%(23 / 40)$ men] to receive treatment between July 2011 and August 2014. Table 1 shows the patients' characteristics. Of all patients, 95\% (38/40) had adenocarcinoma, 75.0\% (30/40) had stage IV disease, and 57.5\% (23/ 40) had EGFR mutations.

The 40 eligible patients were administered a median of four cycles (range, 1-4 cycles) of induction chemotherapy comprising cisplatin, pemetrexed, and bevacizumab. Of these patients, 35 (87.5\%) were administered maintenance chemotherapy comprising pemetrexed and bevacizumab for a median of nine cycles (range, 1-54 cycles) (Table 2). Reasons for induction chemotherapy discontinuation were disease progression $(n=1)$, unacceptable toxicity $(n=3)$, and patient request $(n=1)$.

\section{Toxicity}

Table 3 shows the grade 3 or 4 treatment-related toxicities that developed in the patients. The proportion of patients developing toxicities graded $\geq 3$ included $15.0 \%$ with neutropenia, $15.0 \%$ with anemia, $7.5 \%$ with hypertension, $7.5 \%$ with anorexia, $7.5 \%$ with fatigue, $5 \%$ with a thromboembolic event, $5 \%$ with jaw osteonecrosis, $2.5 \%$ with

Table 3 Therapy toxicities ( $\geq$ Grade 3 )

\begin{tabular}{lll}
\hline & Grade 3 & Grade 4 \\
\hline Neutropenia & $5(12.5 \%)$ & $1(2.5 \%)$ \\
Anemia & $6(15.0 \%)$ & $0(0 \%)$ \\
Hypertension & $3(7.5 \%)$ & $0(0 \%)$ \\
Anorexia & $3(7.5 \%)$ & $0(0 \%)$ \\
Fatigue & $3(7.5 \%)$ & $0(0 \%)$ \\
Thromboembolic event & $2(5.0 \%)$ & $0(0 \%)$ \\
Jaw osteonecrosis ${ }^{a}$ & $2(5.0 \%)$ & $0(0 \%)$ \\
Nausea & $1(2.5 \%)$ & $0(0 \%)$ \\
Oral mucositis & $1(2.5 \%)$ & $0(0 \%)$ \\
Tumor pain & $1(2.5 \%)$ & $0(0 \%)$ \\
Hyponatremia & $1(2.5 \%)$ & $0(0 \%)$ \\
Gastrointestinal perforation & $0(0 \%)$ & $1(2.5 \%)$ \\
\hline
\end{tabular}

These two patients received denosumab 

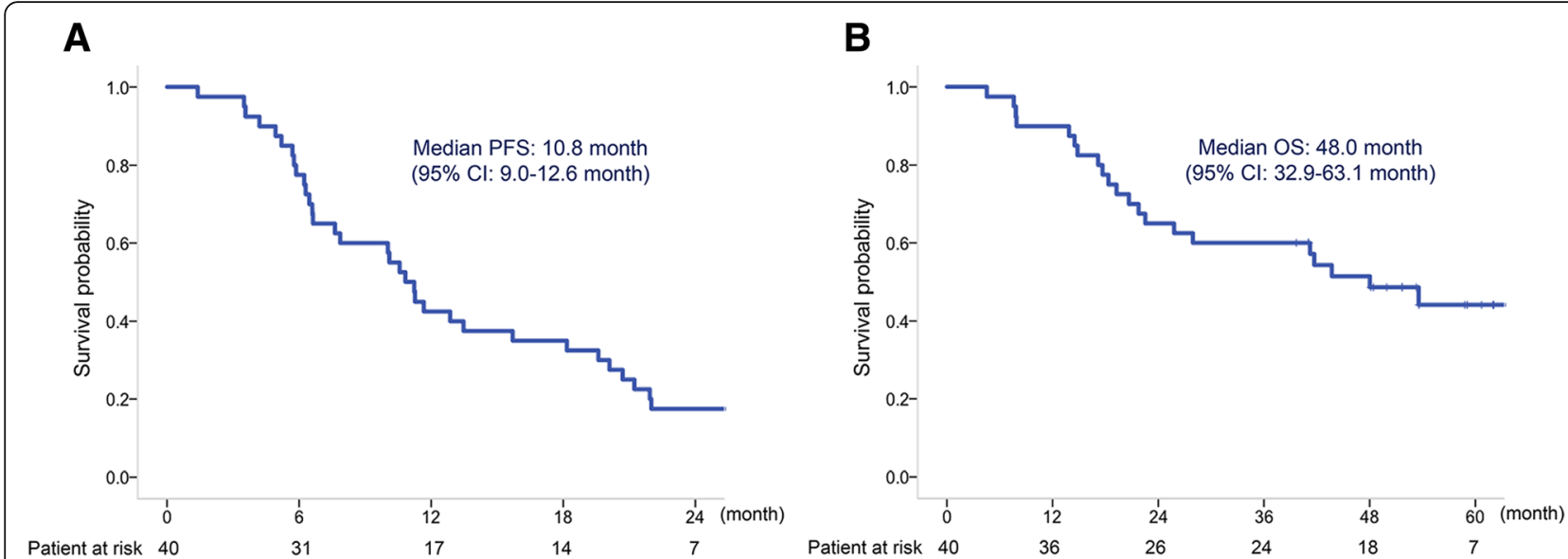

Fig. 1 Progression-free survival (a) and overall survival (b) in patients with advanced or recurrent nonsquamous non-small cell lung cancer $(n=40)$

nausea, $2.5 \%$ with oral mucositis, $2.5 \%$ with tumor pain, $2.5 \%$ with hyponatremia, and $2.5 \%$ with gastrointestinal perforation. There were no treatment-related deaths.

\section{Efficacy outcomes}

This study met the primary endpoint. Median PFS was 10.8 (95\% CI, 9.0-12.6), and OS was 48.0 (95\% CI, 32.963.1) months (Fig. 1a and b). The objective response rate was $70.6 \%$, and the disease control rate was $97.1 \%$ in patients with a measurable target lesion $(n=34)$ (Table 2). On analyzing the relative change in the tumor size from the baseline, we found that all patients (34/34) experienced some degree of tumor shrinkage (Fig. 2).

The median PFS of patients with EGFR mutations $(n=23)$ and those without the mutation $(n=16)$ were 12.9 (95\% CI, 9.4-16.3) and 7.9 (95\% CI, 1.1-14.7) months, respectively $(P=0.36$, Fig. 3a). Patients with EGFR mutations $(n=23)$ did not reach a median OS, and those without the mutation $(n=16)$ had a median
OS of 20.7 (95\% CI, 15.8-25.6) months $(P=0.004$; Fig. 3b).

\section{Discussion}

We demonstrated the safety and efficacy of induction therapy using cisplatin $\left(75 \mathrm{mg} / \mathrm{m}^{2}\right)$, pemetrexed $(500 \mathrm{mg} /$ $\left.\mathrm{m}^{2}\right)$, and bevacizumab $(15 \mathrm{mg} / \mathrm{kg})$ followed by maintenance therapy with pemetrexed $\left(500 \mathrm{mg} / \mathrm{m}^{2}\right)$ and bevacizumab $(15 \mathrm{mg} / \mathrm{kg})$ in patients with advanced or recurrent nonsquamous NSCLC. Non-hematological toxicities graded higher than 3 were not found in $10 \%$ of the patients, and a grade 4 non-hematological toxicity (gastrointestinal perforation) developed in only one (2.5\%) patient. Furthermore, there was no treatment-related death in this study. The low frequencies of severe toxicities observed in this study are consistent with those observed in other studies $[7,11]$. Serious adverse events such as pulmonary embolism (1.6\%) and pneumonia (5.6\%) occurred during maintenance therapy with pemetrexed and

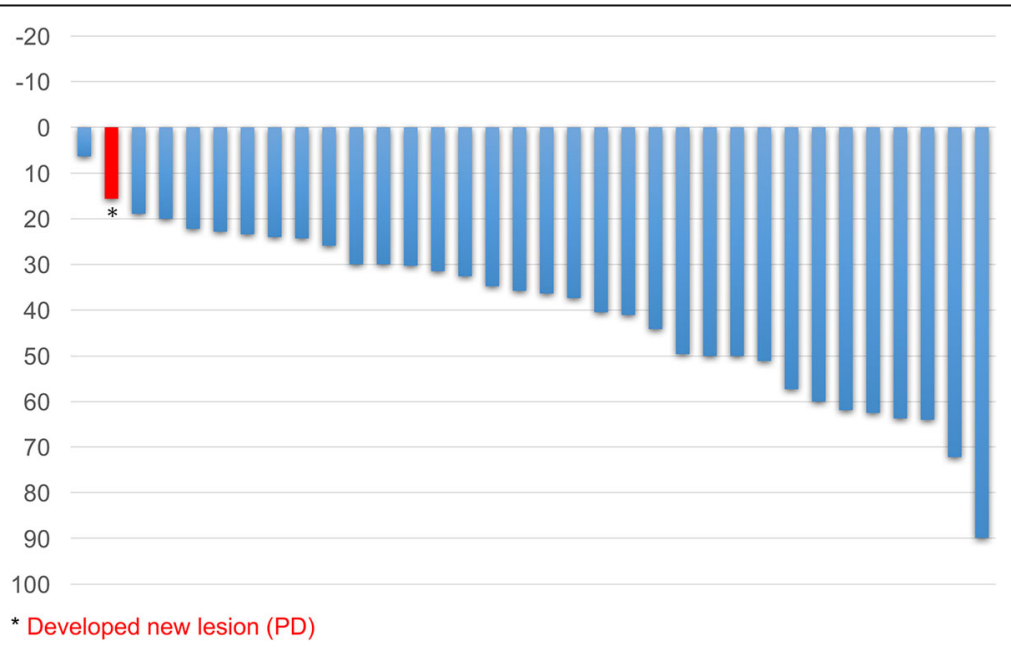

Fig. 2 Best percentage change from the baseline in the sum of longest diameters of target lesions $(n=34)$ 

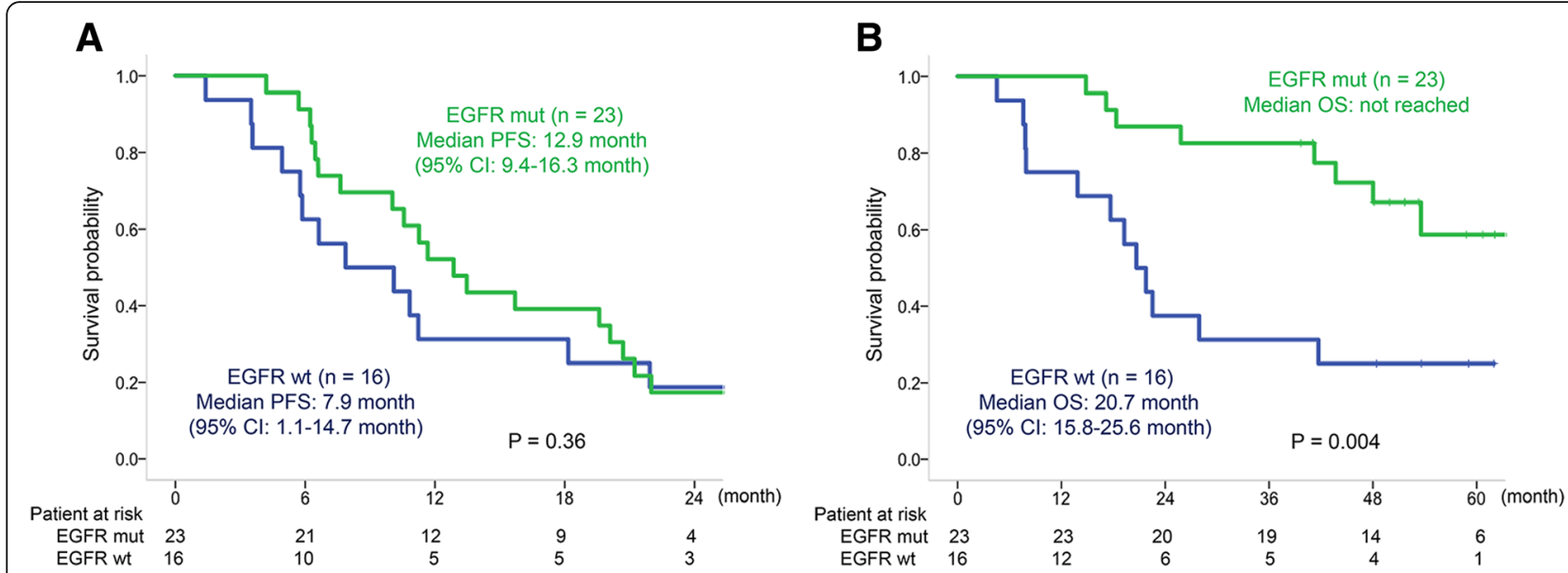

Fig. 3 Progression-free survival (a) and overall survival (b) in patient subgroups based on their EGFR mutation status

bevacizumab in the AVAPERL study, in which the bevacizumab dose was $7.5 \mathrm{mg} / \mathrm{kg}$ [7]. A retrospective study evaluating the feasibility of cisplatin, pemetrexed, and bevacizumab $(15 \mathrm{mg} / \mathrm{kg})$ in patients with advanced nonsquamous NSCLC reported low frequencies of grade $3 / 4$ non-hematologic toxicities (hypertension, 13\%; pulmonary thromboembolism, $3 \%$; fatigue, $3 \%$; anorexia, $6 \%$; gastric ulcer, 3\%; and colitis, $3 \%$ ) and no treatment-related deaths [11]. To the best of our knowledge, this is the first prospective study evaluating $15 \mathrm{mg} / \mathrm{kg}$ of bevacizumab in combination with standard dose cisplatin and pemetrexed for patients with nonsquamous NSCLC; our results suggest that the dose of $15 \mathrm{mg} / \mathrm{kg}$ bevacizumab and combination therapy with cisplatin, pemetrexed, and bevacizumab followed by maintenance therapy with pemetrexed and bevacizumab is a safe and feasible regimen.

Regarding efficacy, this study met its primary endpoint with a median PFS of 10.8 months, which is consistent with the results of the phase III AVAPERL study (median PFS from induction treatment, 10.2 months) [7], and seems superior to those of the PointBreak study (carboplatin, pemetrexed, and bevacizumab followed by pemetrexed and bevacizumab: the median PFS from induction of treatment, 8.6 months) [9] and those of the Pronounce study (carboplatin plus pemetrexed followed by pemetrexed: the median PFS from induction of treatment, 4.44 months) [12] (Table 4). The objective response rate of $70.6 \%$ in the present study is also excellent.

This study included $57.5 \%$ patients with EGFR mutations. In our EGFR status-based sub-analysis, PFS of patients with EGFR mutations seemed longer (median PFS, 12.9 months) than that of those without the mutations (median PFS, 7.9 months); however, this difference was not significant. PFS of patients with EGFR mutations who received cisplatin, pemetrexed, and bevacizumab in the present study was similar to that of those who received EGFR-TKIs in other studies (gefitinib, PFS of 9.2-10.8 months; erlotinib, PFS of 9.7-13.1 months; and afatinib, PFS of 11-11.1 months) [13-18]. The standard first-line treatment of patients with advanced NSCLC and with EGFR mutation usually includes EGFR-TKIs; however, a large retrospective study in a real world clinical setting suggested that in patients with NSCLC and EGFR mutations, sequential use of chemotherapy in addition to EGFR-TKI improved OS compared with the use of EGFR-TKI alone [19]. It is important not to miss the opportunity of using the most effective chemotherapy in such cases. Combination therapy with EFGR-TKI

Table 4 Progression-free survival and overall survival of cisplatin/carboplatin, pemetrexed with or without bevacizumab in patients with nonsquamous non-small cell lung cancer

\begin{tabular}{llllll}
\hline Study & Phase & Induction therapy & Maintenance therapy & PFS (months) & OS (months) \\
\hline Scagliotti, et al. [5] & 3 & CDDP + PEM & - & 5.3 & 1.8 \\
PARAMOUNT [6] & 3 & CDDP + PEM & PEM & 6.9 & - \\
AVAPEARL [7] & 3 & CDDP + PEM + BEV & PEM + BEV & 10.2 & NR \\
PointBreak [23] & 3 & CBDCA + PEM + BEV & PEM + BEV & 8.6 & 17.7 \\
PRONOUNCE [12] & 3 & CBDCA + PEM & PEM & 4.44 & 10.5 \\
MAP (The current study) & 2 & CDDP + PEM + BEV & PEM + BEV & 10.8 & 48.0 \\
\hline
\end{tabular}

PFS progression-free survival, OS overall survival, CDDP cisplatin, PEM pemetrexed, BEV bevacizumab, CBDCA carboplatin, NR not reached 
and cytotoxic agents may be another way to avoid missing to use chemotherapy, as a phase II study suggested promising results of concurrent use of gefitinib, carboplatin, and pemetrexed [20]. Additional use of anti-angiogenic treatment is also promising for patients with NSCLC with EGFR mutations. In addition to results of the current study, a randomized phase II study reported that erlotinib with bevacizumab showed better PFS than erlotinib alone [21]. Moreover, a recent phase III study demonstrated that combination therapy with atezolizumab, bevacizumab, carboplatin, and paclitaxel significantly improved PFS and OS compared with bevacizumab, carboplatin, and paclitaxel even in patients with EGFR mutations [22]. Chemotherapy and bevacizumab as well as EGFR-TKI may be potential key drugs to improve prognosis of patients with nonsquamous NSCLC with EGFR mutations. The excellent OS of patients with EGFR mutations in this study, with over 50\% patients with a 5-year OS rate, indicates that induction therapy with cisplatin, pemetrexed, and bevacizumab followed by maintenance therapy with pemetrexed and bevacizumab can be an optional first-line treatment for patients with advanced nonsquamous NSCLC and with EGFR mutations.

\section{Conclusions}

A first-line combination therapy with cisplatin (75 $\left.\mathrm{mg} / \mathrm{m}^{2}\right)$, pemetrexed $\left(500 \mathrm{mg} / \mathrm{m}^{2}\right)$, and bevacizumab $(15 \mathrm{mg} / \mathrm{kg})$ followed by maintenance with pemetrexed $\left(500 \mathrm{mg} / \mathrm{m}^{2}\right)$ and bevacizumab $(15 \mathrm{mg} / \mathrm{kg})$ is safe and effective for patients with stage III, IV, or recurrent nonsquamous NSCLC, and even for those with EGFR mutations.

\section{Abbreviations}

ECOG: Eastern Cooperative Oncology Group; EGFR: Epidermal growth factor receptor; NSCLC: Non-small cell lung cancer; OS: Overall survival; PFS: Progression-free survival; TKI: Tyrosine kinase inhibitor; VEGF: Vascular endothelial growth factor

\section{Acknowledgements \\ The authors would like to thank Enago (www.enago.jp) for the English language review.}

\section{Ethic approval and consent to participate}

The protocol was approved by the institutional review board of Hiroshima University, Hiroshima Prefectural Hospital, Miyoshi Central Hospital, Iwakuni Medical Center, Asa Citizens Hospital, and Yamaguchi University. All patients provided written informed consent.

\section{Funding}

This research received no specific grant from any funding agency in the public, commercial, or not-for-profit sectors.

\section{Availability of data and materials}

Datasets generated during and/or analyzed during the current study are available from the corresponding author on reasonable request.

\section{Authors' contributions}

YT, YM, and MO developed study concepts and design. YT, YM, TM, KF, MD, YA, SK1 (seventh author), SK2 (eighth author), and KU were involved in data acquisition. YT, YM, and $\mathrm{MO}$ were involved in the analysis and interpretation of clinical data. YT was involved in the statistical analysis. YT was involved in drafting the manuscript. YM, TM, KF, MD, YA, SK1, SK2, KU, NH, and MO were involved in revising the manuscript. All authors have read and approved the final manuscript.

\section{Consent for publication}

Not applicable.

\section{Competing interests}

Tsutani Y, Miyata Y, Masuda T, Fujitaka K, Doi M, Awaya Y, Kuyama S, Kitaguchi S, Ueda K, and Hattori $\mathrm{N}$ declare no potential conflicts of interest with any companies/organizations whose products or services may be discussed in this article. Okada M received Consulting fee and Research funding from Chugai Pharmaceutical Co., Ltd., Eli Lilly and Company, and Yakult Honsha Co., Ltd.

\section{Publisher's Note}

Springer Nature remains neutral with regard to jurisdictional claims in published maps and institutional affiliations.

\section{Author details}

'Department of Surgical Oncology, Research Institute for Radiation Biology and Medicine, Hiroshima University, 1-2-3 Kasumi, Minami-ku, Hiroshima 734-8551, Japan. ${ }^{2}$ Department of Respiratory Internal Medicine, Hiroshima University, 1-2-3 Kasumi, Minami-ku, Hiroshima 734-8551, Japan. ${ }^{3}$ Department of Medical Oncology, Hiroshima Prefectural Hospital, 1-5-54, Ujinakanda, Minami-ku, Hiroshima 734-8530, Japan. ${ }^{4}$ Department of Respiratory Medicine, Miyoshi Central Hospital, 10531 Higashisakaya, Miyoshi 728-8502, Japan. ${ }^{5}$ Department of Respiratory Medicine, Iwakuni Medical Center, 1-1-1 Atago, Iwakuni 740-8510, Japan. ${ }^{6}$ Department of Respiratory Medicine, Asa Citizens Hospital, 2-1-1 Kabeminami, Asakita-ku, Hiroshima 731-0293, Japan.

${ }^{7}$ Department of Thoracic Surgery, Yamaguchi University, 1-1-1

Minamikogushi, Ube 755-8505, Japan.

Received: 15 May 2018 Accepted: 28 November 2018

Published online: 10 December 2018

\section{References}

1. Dvorak HF. Vascular permeability factor/vascular endothelial growth factor: a critical cytokine in tumor angiogenesis and a potential target for diagnosis and therapy. J Clin Oncol. 2002;20:4368-80.

2. Dowell JE, Dunphy FR, Taub RN, et al. A multicenter phase II study of cisplatin, pemetrexed, and bevacizumab in patients with advanced malignant mesothelioma. Lung Cancer. 2012;77:567-71.

3. Sandler A, Gray R, Perry MC, et al. Paclitaxel-carboplatin alone or with bevacizumab for non-small-cell lung cancer. N Engl J Med. 2006;355:2542-50.

4. Reck M, von Pawel J, Zatloukal P, et al. Phase III trial of cisplatin plus gemcitabine with either placebo or bevacizumab as first-line therapy for nonsquamous non-small-cell lung cancer: AVAil. J Clin Oncol. 2009;27:1227-34.

5. Scagliotti GV, Parikh P, von Pawel J, et al. Phase III study comparing cisplatin plus gemcitabine with cisplatin plus pemetrexed in chemotherapy-naive patients with advanced-stage non-small-cell lung cancer. J Clin Oncol. 2008; 26:3543-51.

6. Paz-Ares L, de Marinis F, Dediu M, et al. Maintenance therapy with pemetrexed plus best supportive care versus placebo plus best supportive care after induction therapy with pemetrexed plus cisplatin for advanced non-squamous non-small-cell lung cancer (PARAMOUNT): a double-blind, phase 3, randomised controlled trial. Lancet Oncol. 2012;13:247-55.

7. Barlesi F, Scherpereel A, Rittmeyer A, et al. Randomized phase III trial of maintenance bevacizumab with or without pemetrexed after first-line induction with bevacizumab, cisplatin, and pemetrexed in advanced nonsquamous non-small cell lung cancer: AVAPERL (M022089). J Clin Oncol. 2013;31:3004-11.

8. Eisenhauer EA, Therasse P, Bogaerts J, et al. New response evaluation criteria in solid tumours: revised RECIST guideline (version 1.1). Eur J Cancer. 2009; 45:228-47.

9. Yokoi T, Torii Y, Katashiba Y, et al. Phase II study of pemetrexed and carboplatin plus bevacizumab, followed by maintenance pemetrexed and bevacizuman in Japanese patients with non-squamous non-small cell lung cancer. Oncol Lett. 2014;8:2453-7. 
10. Weiss JM, Villaruz LC, O'Brien J, et al. Results of a phase II trial of carboplatin, pemetrexed, and bevacizumab for the treatment of never or former/light smoking patients with stage IV non-small cell lung cancer. Clin Lung Cancer. 2016:17:128-32.

11. Hirai F, Seto T, Inamasu E, et al. Feasibility of cisplatin/pemetrexed with 15 $\mathrm{mg} / \mathrm{kg}$ bevacizumab for the treatment of patients with advanced nonsquamous non-small cell lung cancer. Oncol Lett. 2015;9:2577-82.

12. Zinner RG, Obasaju CK, Spigel DR, et al. PRONOUNCE: randomized, openlabel, phase III study of first-line pemetrexed + carboplatin followed by maintenance pemetrexed versus paclitaxel + carboplatin + bevacizumab followed by maintenance bevacizumab in patients with advanced nonsquamous non-small cell lung cancer. J Thorac Oncol. 2015;10:134-42.

13. Mitsudomi T, Morita S, Yatabe Y, et al. Gefitinib versus cisplatin plus docetaxel in patients with non-small-cell lung cancer harbouring mutation of the epidermal growth factor receptor (WJTOG3405): an open label, randomized phase 3 trial. Lancet Oncol. 2010;11:121-8.

14. Maemondo M, Inoue A, Kobayashi K, et al. Gefitinib or chemotherapy for non-small-cell lung cancer with mutated EGFR. N Engl J Med. 2010;362: 2380-8.

15. Zhou C, Wu YL, Chen G, et al. Erlotinib versus chemotherapy as first-line treatment for patients with advanced EGFR mutation-positive non-small-cell lung cancer (OPTIMAL, CTONG-0802): a multicenter, open-label, randomized, phase 3 study. Lancet Oncol. 2011;12:735-42.

16. Rosell R, Carcereny E, Gervais R, et al. Erlotinib versus standard chemotherapy as first-line treatment for European patients with advanced EGFR mutation-positive non-small-cell lung cancer (EURTAC): a multicenter, open-label, randomized phase 3 trial. Lancet Oncol. 2012;13:239-46.

17. Sequist LV, Yang JC, Yamamoto N, et al. Phase III study of afatinib or cisplatin plus pemetrexed in patients with metastatic lung adenocarcinoma with EGFR mutations. J Clin Oncol. 2013;31:3327-34.

18. Wu YL, Zhou C, Hu CP, et al. Afatinib versus cisplatin plus gemcitabine for first-line treatment of Asian patients with advanced non-small-cell lung cancer harbouring EGFR mutations (LUX-lung 6): an open-label, randomized phase 3 trial. Lancet Oncol. 2014;15:213-22.

19. Okamoto I, Morita S, Tashiro N, et al. Real world treatment and outcomes in EGFR mutation-positive non-small cell lung cancer: long-term follow-up of a large patient cohort. Lung Cancer. 2018;117:14-9.

20. Oizumi S, Sugawara S, Minato K, et al. Updated survival outcomes of NEJ005/TCOG0902: a randomised phase II study of concurrent versus sequential alternating gefitinib and chemotherapy in previously untreated non-small cell lung cancer with sensitive EGFR mutations. ESMO Open. 2018:3:e000313.

21. Seto T, Kato T, Nishio M, et al. Erlotinib alone or with bevaizumab as firstline therapy in patients with advanced non-squamous non-small cell lung cancer harbouring EGFR mutations (JO25567): an open-label, randomised, multicentre, phase 2 study. Lancet Oncol. 2014:15:1236-44.

22. Socinski MA, Jotte RM, Cappuzzo F, et al. Atezolizumab for first-line treatment of metastatic nonsquamous NSCLC. N Engl J Med. 2018;378: 2288-301.

23. Patel JD, Socinski MA, Garon EB, et al. PointBreak: a randomized phase III study of pemetrexed plus carboplatin and bevacizumab followed by maintenance pemetrexed and bevacizumab versus paclitaxel plus carboplatin and bevacizumab followed by maintenance bevacizumab in patients with stage IIIB or IV nonsquamous non-small cell lung cancer. J Clin Oncol. 2013:31:4349-57.

Ready to submit your research? Choose BMC and benefit from:

- fast, convenient online submission

- thorough peer review by experienced researchers in your field

- rapid publication on acceptance

- support for research data, including large and complex data types

- gold Open Access which fosters wider collaboration and increased citations

- maximum visibility for your research: over $100 \mathrm{M}$ website views per year

At BMC, research is always in progress.

Learn more biomedcentral.com/submissions 